ORIGINAL ARTICLE

\title{
Diabetes care provision and glycaemic control in Northern Ireland: a UK regional audit
}

\author{
C R Cardwell, C C Patterson, M Allen, D J Carson, on behalf of the Northern Ireland Paediatric \\ Diabetes Study Group
}

See end of article for authors' affiliations

.....................

Correspondence to: Mr C R Cardwell, Department of Epidemiology \& Public Health, The Queen's University of Belfast, Grosvenor Road, Belfast BT12 6BJ, Northern Ireland, UK; c.cardwell@ qub.ac.uk

Accepted 7 February 2005

\begin{abstract}
Aims: To assess the care received, compared to national guidelines, and to investigate factors associated with glycaemic control in children and adolescents with type 1 diabetes attending clinics in Northern Ireland.

Methods: An audit of the care provided to all patients attending 11 paediatric diabetes clinics commenced in 2002. A research nurse interviewed 914 patients completing a questionnaire recording characteristics, social circumstances, and aspects of diabetes management, including the monitoring of complications and access to members of the diabetes team. Glycaemic control was measured by glycosylated haemoglobin $\left(\mathrm{HbA}_{1 \mathrm{c}}\right)$, determined at a DCCT aligned central laboratory.

Results: The average $\mathrm{HbA}_{1 c}$ concentration was $8.8 \%$ (SD 1.5\%), with $20 \%$ of patients achieving recommended $\mathrm{HbA}_{1 c}$ levels of less than $7.5 \%$. In the year prior to the audit, $76 \%$ of patients were reviewed by a diabetes specialist nurse and $42 \%$ were tested for microalbuminuria. After adjustment for confounding factors, better glycaemic control was identified, particularly in patients who had attended exactly four diabetes clinics in the previous year, were members of the patient association Diabetes UK, and lived with both natural parents.

Conclusions: In Northern Ireland only a minority of patients achieved recommended $\mathrm{HbA}_{1 \mathrm{c}}$ levels. Furthermore, children and adolescents with diabetes were reviewed by fewer specialists and were less intensively monitored for microvascular complications than recommended. There was evidence of better control in children who were members of Diabetes UK, suggesting that parental attitude and involvement could lead to benefits.
\end{abstract}

G ood glycaemic control in children and adolescents with type 1 diabetes has been associated with better quality of life ${ }^{1}$ and reduced or delayed development of long term complications. ${ }^{2}{ }^{3}$ The structure of an appropriate multi-professional team was recommended in the UK by The principles of good practice for the care of young people with diabetes. ${ }^{4}$ The provision of these services has been surveyed on three occasions between 1988 and $1999,^{5-7}$ and although few clinics achieve all standards, results have improved over time. However, information was obtained from questionnaires completed by paediatricians without reference to individual patients or their medical records.

The provision of a motivated multi-disciplinary team of diabetes specialists $^{89}$ is thought to be vital in attaining optimal glycaemic control. However, international ${ }^{10}$ and national cross-sectional studies ${ }^{11-14}$ continue to report glycosylated haemoglobin $\left(\mathrm{HbA}_{\mathrm{Ic}}\right)$ results for the majority of patients above the levels desirable to minimise the risk of complications in adulthood. Various factors have been identified which are associated with glycaemic control, ${ }^{10}{ }^{12}{ }^{13}{ }^{15-20}$ but further work is required..$^{21}$

The goals of this audit were to identify all patients attending paediatric diabetes clinics in Northern Ireland and obtain information about the care received over the previous 12 months directly from patients and/or their parents and from medical records. The audit also determined $\mathrm{HbA}_{\mathrm{lc}}$ levels for these patients and investigated factors associated with glycaemic control.

\section{RESEARCH DESIGN AND METHODS}

Between April 2002 and June 2003 all children and adolescents attending 11 paediatric diabetes clinics in
Northern Ireland were invited to participate. An estimated ascertainment rate was calculated as the percentage of patients on the Northern Ireland childhood type 1 diabetes register $^{22}$ on 1 January 2002, under 15 years of age, still resident in Northern Ireland, and not attending adult clinics, who were included in the audit. A single research nurse collected information during routine outpatient visits. Families missing their appointments were interviewed at a subsequent appointment. For each patient a structured questionnaire was completed recording characteristics (including age, weight, height, duration of diabetes, postcode of usual address, clinical history, and family history of autoimmune disease), aspects of diabetes management (including insulin dosage, blood glucose monitoring, attendance at clinics, occurrence of severe hypoglycaemia, and other complications), and social factors (including social class and family circumstances). This questionnaire also recorded contacts with healthcare specialists and the monitoring of complications over the previous 12 months; simultaneously, this information was independently retrieved from hospital case notes. Hypoglycaemic episodes were considered severe if intramuscular glucagon or intravenous glucose was administered. Finally, a $50 \mu \mathrm{l}$ blood sample was taken and $\mathrm{HbA}_{\mathrm{lc}}$ measured at the Special Investigations Haematology Laboratory, Royal Group Hospitals Trust, Belfast by a DCCT aligned HPLC method.

Audit criteria were adapted from the third national UK survey $^{7}$ and from the International Society for Pediatric and Adolescent Diabetes recommendations. ${ }^{23}$ Analysis of audit criteria were conducted in patients whose diabetes had been diagnosed for at least 12 months prior to interview, as many criteria refer to care in that period. 


\begin{tabular}{|c|c|c|}
\hline Characteristic & Mean (SD) & $n(\%)$ \\
\hline \multicolumn{3}{|l|}{ Gender } \\
\hline Males & & 473 (51.8) \\
\hline Females & & 441 (48.3) \\
\hline Age at visit (years) & \multirow[t]{5}{*}{$11.8(4.0)$} & - \\
\hline $0-5$ & & 93 (10.2) \\
\hline $6-10$ & & 259 (28.3) \\
\hline $11-15$ & & $434(47.5)$ \\
\hline $16+$ & & 128 (14.0) \\
\hline Age at diagnosis (years) & \multirow[t]{5}{*}{$7.23(3.8)$} & \\
\hline $0-5$ & & $382(41.8)$ \\
\hline $6-10$ & & 341 (37.3) \\
\hline $11-15$ & & $190(20.8)$ \\
\hline $16+$ & & $1(0.1)$ \\
\hline Height (SDS) & \multirow[t]{6}{*}{$0.04(1.2)$} & \\
\hline Less than -2 SD & & $38(4.2)$ \\
\hline$-2 S D$ to $-1 S D$ & & $96(10.6)$ \\
\hline$-1 S D$ to $+1 S D$ & & $600(65.9)$ \\
\hline $1 \mathrm{SD}$ to $2 \mathrm{SD}$ & & 147 (16.2) \\
\hline Over 2 SD & & $29(3.2)$ \\
\hline Weight (SDS) & \multirow[t]{6}{*}{$0.68(1.0)$} & \\
\hline Less than -2 SD & & $8(0.9)$ \\
\hline$-2 S D$ to $-1 S D$ & & $37(4.1)$ \\
\hline$-1 S D$ to $+1 S D$ & & $520(57.1)$ \\
\hline $1 S D$ to $2 S D$ & & $266(29.2)$ \\
\hline Over 2 SD & & $79(8.7)$ \\
\hline BMI (SDS) & \multirow[t]{6}{*}{$0.86(1.0)$} & \\
\hline Less than -2 SD & & $5(0.6)$ \\
\hline$-2 S D$ to $-1 S D$ & & $20(2.2)$ \\
\hline$-1 S D$ to $+1 S D$ & & $463(50.9)$ \\
\hline $1 S D$ to $2 S D$ & & 320 (35.2) \\
\hline Over 2 SD & & 102 (11.2) \\
\hline Duration of diabetes & \multirow[t]{5}{*}{$4.6(3.8)$} & - \\
\hline $0-12$ months & & $136(14.8)$ \\
\hline $12-18$ months & & $112(12.3)$ \\
\hline 19 months -5 years & & 391 (42.8) \\
\hline Over 5 years & & $275(30.1)$ \\
\hline
\end{tabular}

Analysis of glycaemic control, severe hypoglycaemic episodes, and readmissions for diabetic ketoacidosis (DKA) were restricted to patients interviewed prior to their 16th birthday as coverage of older patients was considered less complete. Patients whose diabetes had been diagnosed for less than 12 months who may be in a phase of partial remission were also excluded. A deprivation score was calculated for each postcode based on the Carstairs index, derived from four 1991 census indicators: unemployment, car ownership, social class, and household crowding. ${ }^{24}$

\section{Statistical analysis}

Height, weight, and BMI were converted into standard deviation scores (SDS) to take account of children's gender and age using the 1990 British Growth Standard ${ }^{25}$ and then divided by quintiles into fifths. The mean and standard deviation of $\mathrm{HbA}_{\mathrm{lc}}$ was obtained for each category of potential explanatory variables and compared using $t$ tests and one way analysis of variance. Multiple regression analysis was conducted controlling first for sex, age, and duration (in categories), as these were factors over which clinics had no control, and then for other factors on a variable-by-variable basis. Rates of DKA and severe hypoglycaemic episodes were calculated and a $\chi^{2}$ test used to compare severe hypoglycaemia by $\mathrm{HbA}_{\mathrm{lc}}$ level (categorised as $>7.5 \%$ or $\leqslant 7.5 \%)$.

Statistical analyses were performed using STATA release 8.0 (Stata Corporation, College Station, Texas).

\section{RESULTS}

There were 914 patients included in the audit, all Caucasian, and none with type 2 diabetes. Other patient characteristics are shown in table 1 . The estimated ascertainment rate was $97.4 \%$.

There were 778 patients whose diabetes had been diagnosed for at least one year. Review and monitoring of complications by healthcare specialists are shown in table 2 .

Mean $\mathrm{HbA}_{\mathrm{lc}}$ was $8.8 \%$, standard deviation $1.53 \%$, in the $95 \%(621 / 651)$ of patients, interviewed prior to their 16th birthday whose diabetes had been diagnosed for at least one year, for whom this was available. Comparison of $\mathrm{HbA}_{\mathrm{lc}}$ levels in subgroups of these 621 patients are shown in table 3 (sociodemographic factors) and table 4 (clinic related factors). These tables show comparisons with a reference category for each patient characteristic after controlling for sex, age, and duration.

In table 3 the unadjusted analysis shows that age, pubertal status, duration of diabetes, SDS height, and SDS weight were all significantly associated with $\mathrm{HbA}_{\mathrm{lc}}$ level. The association with age was independent of sex and duration $(\mathrm{p}<0.0001)$ and the association with duration was independent of age and sex $(p=0.01)$. Patients who were not living with both their natural parents had a significantly higher $\mathrm{HbA}_{1 \mathrm{c}}$ by an estimated $0.55 \%$ (95\% CI $0.22 \%$ to $0.88 \%$ ) after adjusting for sex, age, and duration. Although parental occupation was significantly associated both before $(p=0.0004)$ and after adjustment $(p=0.005)$, the effect was attributable to high $\mathrm{HbA}_{1 \mathrm{c}}$ levels in those patients where the head of the household's occupation could not be classified (for example, never worked, long term unemployed, or armed forces).

In table 4 the crude analysis shows that the number of blood glucose tests per day, number of $\mathrm{HbA}_{1 \mathrm{c}}$ tests, number of doses of insulin, and total insulin dose were all associated with $\mathrm{HbA}_{1 \mathrm{c}}$ level. However, some of these associations could be attributed to other factors. After adjustment for sex, age, and duration the associations between the number of doses of insulin per day and the total insulin dose were no longer significant. After additionally adjusting for the attended diabetes clinic the associations between both number of blood glucose tests per day $(\mathrm{p}=0.21)$ and number of $\mathrm{HbA}_{\mathrm{lc}}$ tests $(p=0.10)$ were no longer significant.

The number of diabetes clinic attendances was associated with $\mathrm{HbA}_{\mathrm{Ic}}$ level both before and after adjustment. Specifically, after adjusting for sex, age, and duration, those patients attending less than four clinics in the last year had a significantly higher $\mathrm{HbA}_{\mathrm{lc}}$ level by an estimated $0.42 \%(95 \%$ CI $0.14 \%$ to $0.70 \%$ ) compared to those attending exactly four clinics, while those attending more than four clinics had a higher $\mathrm{HbA}_{\mathrm{Ic}}$ level by an estimated $0.32 \%$ (95\% CI $0.03 \%$ to $0.61 \%$ ) compared to those attending exactly four clinics. Members of Diabetes UK had a significantly lower $\mathrm{HbA}_{\mathrm{lc}}$ by an estimated $0.49 \%$ (95\% CI $0.26 \%$ to $0.73 \%$ ), after adjustment for sex, age, and duration. Other factors investigated for which no association between $\mathrm{HbA}_{\mathrm{lc}}$ was detected included season of visit and time from home to clinic. The model containing sex, age, duration, clinic attendance, natural parents, and Diabetes UK membership explained 13\% $\left(\mathrm{R}^{2}=0.13\right)$ of patient-to-patient variation in $\mathrm{HbA}_{\mathrm{lc}}$ levels; adding clinic to this model raised the figure to $21 \%$, indicating that clinic-to-clinic differences in $\mathrm{HbA}_{\mathrm{Ic}}$ values remained that could not be explained by the available patient characteristics.

There were 92 patients (14\%), interviewed prior to their 16th birthday whose diabetes had been diagnosed for at least one year, who reported 191 severe hypoglycaemic episodes in the previous year, which corresponded to 29.5 episodes per 100 person-years. In contrast, the hospital chart recorded a 
Table 2 Compliance with audit criteria, taken from hospital charts, of patients attending paediatric diabetes clinics in Northern Ireland whose diabetes had been diagnosed for at least one year $(n=778)$ and for children over 11 years of age $(n=452)$

\begin{tabular}{|c|c|c|}
\hline Audit criteria & $\begin{array}{l}\text { All children } \\
\mathrm{n}(\%)\end{array}$ & $\begin{array}{l}\text { Patients } \geqslant 12 \\
\text { years } \\
\mathrm{n}(\%)\end{array}$ \\
\hline \multicolumn{3}{|c|}{$\begin{array}{l}\text { Reviewed at any clinic appointment in the } 12 \text { month period prior to } \\
\text { interview by: }\end{array}$} \\
\hline Diabetes specialist nurse* $†$ & $589(75.7)$ & \\
\hline Dietician*† ${ }^{*}$ & 575 (73.9) & \\
\hline Psychologist & $23(3.0)$ & \\
\hline Podiatrist $^{\star}$ & $195(25.1)$ & \\
\hline \multicolumn{3}{|c|}{ Contactt in the 12 month period prior to interview by: } \\
\hline Diabetes specialist nurse & $61(7.9)$ & \\
\hline Doctor & $16(2.1)$ & \\
\hline \multicolumn{3}{|c|}{ Complications monitored in 12 months prior to interview by conducting: } \\
\hline Retinal examination* $\dagger$ & $432(55.5)$ & $277(61.3)$ \\
\hline Test for microalbuminuria* $\dagger$ & $327(42.0)$ & $197(43.6)$ \\
\hline Blood pressure measurement† & $603(77.5)$ & $360(79.7)$ \\
\hline Injection site check* & $745(96.1)$ & \\
\hline Foot check*§ & $533(68.5)$ & \\
\hline Growth plotted*ศ & $488(75.0)^{* *}$ & \\
\hline \multicolumn{3}{|l|}{$\mathrm{HbA}_{1 c}$} \\
\hline $\mathrm{HbA}_{1 \mathrm{c}}$ measurement at each visit $\dagger$ & 735 (95.2) & \\
\hline $\mathrm{HbA}_{1 \mathrm{c}}$ measurement $\leqslant 7.5 \%^{*}+\dagger$ & $124(20.0)^{* *}$ & \\
\hline \multicolumn{3}{|c|}{$\begin{array}{l}\text { *Adapted from ISPAD recommendations. } \\
\text { †Adapted from BDA (now Diabetes UK) recommendations. } \\
\text { tExcluding clinic appointment, e.g. house visit or telephone call. } \\
\text { \$Foot check conducted by either podiatrist, doctor, or nurse. } \\
\text { 9Height and weight plotted on a growth chart. } \\
\text { **Only calculated for children less than } 16 \text { years old. } \\
\text { ††Defermined at audit visit. }\end{array}$} \\
\hline
\end{tabular}

total of 13 severe hypoglycaemic episodes, a rate of 2.0 per 100 person-years, occurring in $1 \%(8 / 648)$ of patients. There was no significant difference $(\mathrm{p}=0.27)$ in the prevalence of severe hypoglycaemia by $\mathrm{HbA}_{1 \mathrm{c}}$; patients with $\mathrm{HbA}_{1 \mathrm{c}} \leqslant 7.5 \%$ experienced a rate of 25.0 episodes per 100 person-years compared with 31.1 in patients with $\mathrm{HbA}_{1 \mathrm{c}}>7.5 \%$. There was little difference between the chart and interview record of readmissions for DKA; overall the chart recorded 7.1 DKA episodes per 100 person-years, which occurred in 6\% (36/649) of the children.

\section{DISCUSSION}

This is the first audit of the care provided to children and adolescents with type 1 diabetes in Northern Ireland. Glycaemic control, mean $\mathrm{HbA}_{\mathrm{lc}} 8.8 \%$, was roughly comparable to other similar national audits from Scotland, ${ }^{13}$ France, ${ }^{12}$ and two audits from Denmark ${ }^{11}{ }^{14}$ (mean $\mathrm{HbA}_{\mathrm{lc}}$ $8.9 \%, 9.0 \%, 9.1 \%$, and $8.7 \%$, respectively). However, the small percentage, $20 \%$, of patients achieving recommended $\mathrm{HbA}_{1 \mathrm{c}}$ levels, ${ }^{23} \leqslant 7.5 \%$, is a cause for concern.

The lack of patients receiving an annual review by all members of the paediatric diabetes specialist team may reflect the failure to meet healthcare staffing recommendations. In particular, throughout Northern Ireland there were only 2.5 whole time equivalent (WTE) diabetes specialist nurses in post compared with the 9 diabetes specialist nurses recommended $^{26}$ for a clinic population of 914 . Similarly, the low proportion of patients reviewed by a clinical psychologist may also reflect staff shortages rather than a lack of need for psychological input among children with persistently poor glycaemic control. ${ }^{27}$

Monitoring of children and adolescents for microvascular complications, particularly microalbuminuria and retinal examinations, fell below recommendations. ${ }^{23}$ This study shows how the deficiencies in diabetes services, based on a recent UK survey of consultant paediatricians, ${ }^{7}$ translate to deficiencies in the care received by patients. Importantly, this is the first study that is likely to accurately reflect the levels of care provided in the UK as information was directly recorded from parents/carers and was confirmed by chart review. In contrast, the previously mentioned survey relied on the perceptions of consultant paediatricians who were responsible for providing diabetes services. Two other UK audits, ${ }^{13} 2829$ to our knowledge the only UK audits of similar size and ascertainment rate, did not present information on care received directly recorded from the patient/carer.

The observation that less than $10 \%$ of children stating they had experienced severe hypoglycaemic episodes in the past year had this recorded in their hospital chart suggests that these episodes may not be receiving adequate attention at clinic visits. Furthermore, this result indicates that comparisons of severe hypoglycaemia between centres must be interpreted with caution.

The observed associations between $\mathrm{HbA}_{\mathrm{lc}}$ level and age and diabetes duration and the lack of association with gender, were mostly consistent with previous large cross-sectional studies. ${ }^{1012} 13$ Earlier studies have also observed $\mathrm{HbA}_{\mathrm{lc}}$ associations with total insulin dosage $e^{1213161820}$ and the number of insulin doses per day, ${ }^{12}{ }^{13}$ but in this study these associations could be explained by the duration of diabetes and the age of the patients. However, poorer control was noted in children prescribed four doses of insulin per day, which may reflect that this insulin regime is used for children with poor control or that it may be associated with poor compliance. The evidence supporting the concept that increased blood glucose testing improved control, a consistent finding in previous studies, ${ }^{12}{ }^{16}{ }^{18}$ was less conclusive. An increase in the number of blood glucose tests was associated with a decrease in $\mathrm{HbA}_{1 \mathrm{c}}$, but after adjusting for the attended diabetes clinic this effect was no longer apparent, suggesting that it may be explained by other clinic practices.

Glycaemic control was independently associated with Diabetes UK membership, diabetic clinic attendance, and living with both natural parents. The reduction in $\mathrm{HbA}_{1 \mathrm{c}}$ with 
Table 3 Comparison of $\mathrm{HbA}_{1 c}$ results by patient characteristics in patients interviewed prior to their 16 th birthday whose diabetes had been diagnosed for at least one year $(n=621)$

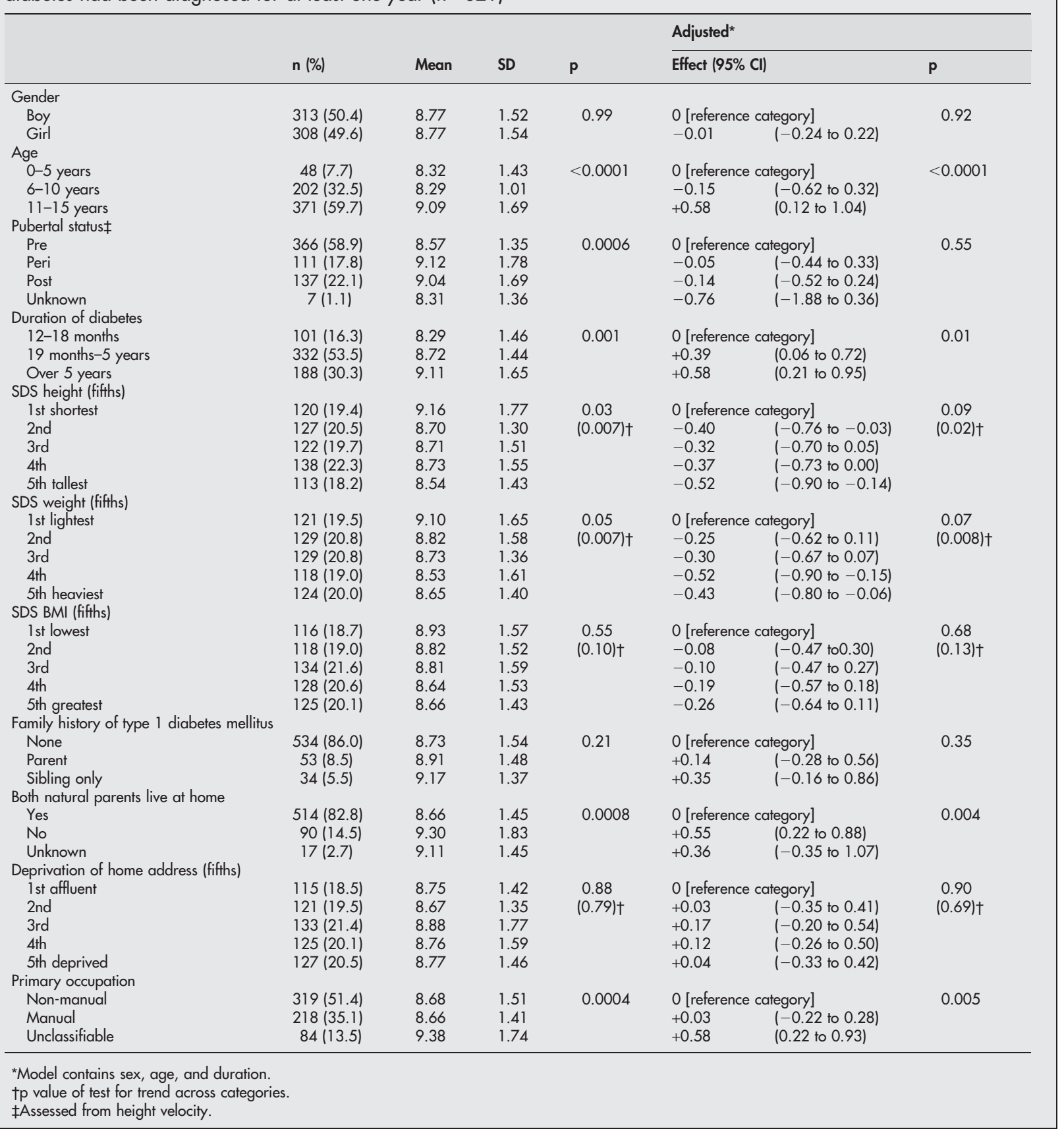

Diabetes UK membership suggests that parental attitude and involvement in the disease could lead to benefits in control. This study confirms an association between infrequent diabetes clinic attendance and worse control that has been noted previously. ${ }^{16}{ }^{17}{ }^{19}$ However, caution should be exercised when interpreting the results in the most frequent category of attendance, as increased attendances could be a consequence rather than a cause of worse control. The worse control of children whose parents have separated has been observed in various studies, ${ }^{13} 1819$ the consistency of this finding indicates that single parents may merit assistance to meet the challenges involved in attaining good control.

In addition to previously mentioned advantages, this study also benefited from a relatively large sample size, a high ascertainment rate, and a detailed questionnaire on established and potential risk factors of poor control. This allowed not only the testing of previous hypotheses but also the adjustment for other risk factors of poor control. This study does have limitations; the cross-sectional design allows the association of factors with good control but not the ability to determine causation which would require a prospective study. Furthermore, the $21 \%$ of $\mathrm{HbA}_{\mathrm{lc}}$ variation that was explained by available variables was similar to a Scottish study, ${ }^{13}$ which accounted for $16 \%$ of $\mathrm{HbA}_{1 \mathrm{c}}$ variation, but indicated that knowledge of factors which establish good control remains incomplete.

In conclusion, the percentage of children and adolescents achieving recommended levels of glycaemic control was disappointing. Furthermore, annual reviews by healthcare specialists and monitoring of microvascular complications fell below recommended levels. Some of these failures may reflect staff shortages, in particular a lack of diabetes 
Table 4 Comparison of $\mathrm{HbAlc}$ results by aspects of diabetes management in patients interviewed by the research nurse prior to their 16 th birthday with duration of diabetes over 1 year $(n=621)$

\begin{tabular}{|c|c|c|c|c|c|c|}
\hline & \multirow[b]{2}{*}{ n (\%) } & \multirow[b]{2}{*}{ Mean } & \multirow[b]{2}{*}{ SD } & \multirow[b]{2}{*}{$\mathbf{p}$} & \multicolumn{2}{|l|}{ Adjusted* } \\
\hline & & & & & Effect $(95 \% \mathrm{Cl})$ & $\mathbf{p}$ \\
\hline \multicolumn{7}{|c|}{ No. of blood glucose tests per day } \\
\hline None & $52(8.4)$ & 9.49 & 1.97 & \multirow[t]{5}{*}{$<0.0001$} & 0 [reference category] & \multirow[t]{5}{*}{0.005} \\
\hline 1 & $103(16.6)$ & 9.10 & 1.51 & & $-0.36 \quad(-0.85$ to 0.13$)$ & \\
\hline 2 & $174(28.0)$ & 8.71 & 1.45 & & $(-1.13$ to -0.22$)$ & \\
\hline 3 & $166(26.7)$ & 8.71 & 1.49 & & $(-1.02$ to -0.09$)$ & \\
\hline$>4$ & $126(20.3)$ & 8.35 & 1.35 & & $(-1.33$ to -0.37$)$ & \\
\hline \multicolumn{7}{|c|}{ No. of $\mathrm{HbA}_{1 c}$ tests in last year } \\
\hline$<4$ & $200(32.5)$ & 9.03 & 1.64 & \multirow[t]{3}{*}{0.004} & $(0.10$ to 0.65$)$ & \multirow[t]{3}{*}{0.03} \\
\hline 4 & $244(39.7)$ & 8.55 & 1.38 & & 0 [reference category] & \\
\hline$>4$ & $171(27.8)$ & 8.72 & 1.51 & & $+0.21 \quad(-0.09$ to 0.65$)$ & \\
\hline \multicolumn{7}{|c|}{ Doses of insulin per day } \\
\hline 1 & $35(5.7)$ & 8.69 & 1.33 & \multirow[t]{4}{*}{0.02} & $(-0.23$ to 0.82$)$ & \multirow[t]{4}{*}{0.07} \\
\hline 2 & $465(75.1)$ & 8.71 & 1.47 & & 0 [reference category] & \\
\hline 3 & $102(16.5)$ & 8.88 & 1.64 & & $-0.14 \quad(-0.46$ to 0.19$)$ & \\
\hline 4 & $17(2.8)$ & 9.84 & 2.30 & & $(0.08$ to 1.51$)$ & \\
\hline \multicolumn{7}{|c|}{ Total insulin dose (U per kg per day) } \\
\hline$<0.5$ & $41(6.6)$ & 8.20 & 1.33 & \multirow[t]{5}{*}{0.0003} & 0 [reference category] & \multirow[t]{5}{*}{0.43} \\
\hline $0.5-0.75$ & $125(20.2)$ & 8.46 & 1.58 & & $+0.11 \quad(-0.43$ to 0.65$)$ & \\
\hline $0.75-1.0$ & 206 (33.2) & 8.70 & 1.48 & & $(-0.25$ to 0.80$)$ & \\
\hline $1-1.25$ & $158(25.5)$ & 9.07 & 1.58 & & $(-0.13$ to 0.98$)$ & \\
\hline$>1.25$ & $90(14.5)$ & 9.07 & 1.40 & & $(-0.27$ to 0.93$)$ & \\
\hline \multicolumn{7}{|c|}{ No. of clinic attendances in last year } \\
\hline$<4$ & $199(32.2)$ & 9.03 & 1.66 & \multirow[t]{3}{*}{0.002} & $+0.42 \quad(0.14$ to 0.70$)$ & \multirow[t]{3}{*}{0.007} \\
\hline 4 & $242(39.1)$ & 8.51 & 1.34 & & 0 [reference category] & \\
\hline$>4$ & $178(28.8)$ & 8.80 & 1.57 & & $+0.32 \quad(0.03$ to 0.61$)$ & \\
\hline \multicolumn{7}{|c|}{ Member of Diabetes UK } \\
\hline No & $243(39.1)$ & 9.08 & 1.67 & \multirow[t]{2}{*}{$<0.0001$} & 0 [reference category] & \multirow[t]{2}{*}{$<0.0001$} \\
\hline Yes & $378(60.9)$ & 8.56 & 1.40 & & $-0.49 \quad(-0.73$ to -0.26$)$ & \\
\hline
\end{tabular}

specialist nurses and clinical psychologists. There was evidence of better control in children who were members of Diabetes UK, who lived with both natural parents, and who attended diabetes clinics regularly.

\section{ACKNOWLEDGEMENTS}

The audit was undertaken with the support and participation of the following members of the Northern Ireland Paediatric Diabetes Study Group: M Allen, T Blair, R Blakely, M Brock, C Cardwell, D Carson, C Corkey, P Cosgrove, N Craig, M Doherty, M Allen, C Gaston, S Griffin, V Gleadhill, C Halahakoon, L Irwin, O McGlone, J Newell, C Patterson, M Quinn, M Rollins, C Stewart, and H Tennet.

\section{Authors' affiliations}

C R Cardwell, C C Patterson, Department of Epidemiology \& Public Health, The Queen's University of Belfast, UK

M Allen, D J Carson, Department of Child Health, The Queen's University of Belfast, UK

Funding for the study was provided by the Regional Multi-professional Audit Group, Department of Health, Social Services, and Public Safety. CRC was in receipt of a Department of Education and Learning grant.

Competing interests: none declared

Ethics approval: ethical approval was obtained from Queen's University Belfast Research Ethics Committee

\section{REFERENCES}

1 Hoey $\mathrm{H}$, Aanstoot $\mathrm{HJ}$, Chiarelli $\mathrm{F}$, et al. Good metabolic control is associated with better quality of life in 2,101 adolescents with type 1 diabetes. Diabetes Care 2001;24:1923-8.

2 McNally PG, Raymond NT, Swift PG, et al. Does the prepubertal duration of diabetes influence the onset of microvascular complications? Diabet Med 1993:10:906-8

3 Diabetes Control and Complications Trial Research Group. Effect of intensive diabetes treatment on the development and progression of long-term complications in adolescents with insulin-dependent diabetes mellitus: Diabetes Control and Complications Trial. J Pediatr 1994;125:177-88.

4 British Diabetic Association. The principles of good practice for the care of young people with diabetes. London: British Diabetic Association, 1995.
5 Anon. The organization of services for children with diabetes in the United Kingdom: report of the British Paediatric Association Working Party. Diabet Med 1990;7:457-64.

6 Haines LC, Swift PG. Report of the 1994 BPA/BDA Survey of Services for Children with Diabetes: Changing Patterns of Care. British Paediatric Association/British Diabetic Association. Diabet Med 1997; 14:693-7.

7 Jefferson IG, Swift PG, Skinner TC, et al. Diabetes services in the UK: third national survey confirms continuing deficiencies. Arch Dis Child 2003:88:53-6.

8 Drash AL. The child, the adolescent, and the Diabetes Control and Complications Trial. Diabetes Care 1993;16:1515-16.

9 Santiago JV. Lessons from the Diabetes Control and Complications Trial. Diabetes 1993:42:1549-54.

10 Mortensen HB, Hougaard P. Comparison of metabolic control in a crosssectional study of 2,873 children and adolescents with IDDM from 18 countries. The Hvidore Study Group on Childhood Diabetes. Diabetes Care 1997:20:714-20.

11 Mortensen HB, Marinelli K, Norgaard K, et al. A nation-wide cross-sectional study of urinary albumin excretion rate, arterial blood pressure and blood glucose control in Danish children with type 1 diabetes mellitus. Danish Study Group of Diabetes in Childhood. Diabet Med 1990;7:887-97.

12 Rosilio M, Cotton JB, Wieliczko MC, et al. Factors associated with glycemic control. A cross-sectional nationwide study in 2,579 French children with type 1 diabetes. The French Pediatric Diabetes Group. Diabetes Care 1998;21:1146-53.

13 Anon. Scottish study group for the care of the young diabetic. Factors influencing glycemic control in young people with type 1 diabetes in Scotland: a population-based study (DIABAUD2). Diabetes Care 2001;24:239-44.

14 Nordly S, Jorgensen T, Andreasen AH, et al. Quality of diabetes management in children and adolescents in Denmark. Diabet Med 2003;20:568-74.

15 Tubiana-Rufi N, Moret L, Czernichow P, et al. Risk factors for poor glycemic control in diabetic children in France. Diabetes Care 1995;18:1479-82.

16 Dorchy H, Roggemans MP, Willems D. Glycated hemoglobin and related factors in diabetic children and adolescents under 18 years of age: a Belgian experience. Diabetes Care 1997;20:2-6.

17 Kaufman FR, Halvorson M, Carpenter S. Association between diabetes control and visits to a multidisciplinary pediatric diabetes clinic. Pediatrics 1999; 103:948-51.

18 Levine BS, Anderson BJ, Butler DA, et al. Predictors of glycemic control and short-term adverse outcomes in youth with type 1 diabetes. J Pediatr 2001;139:197-203.

19 Thompson SJ, Auslander WF, White NH. Comparison of single-mother and two-parent families on metabolic control of children with diabetes. Diabetes Care $2001 ; 24: 234-8$

20 Craig ME, Handelsman P, Donaghue KC, et al. Predictors of glycaemic control and hypoglycaemia in children and adolescents with type 1 diabetes from NSW and the ACT. Med J Aust 2002;177:235-8.

21 Kaufman FR. Searching for glycemic control in pediatric type 1 diabetes: a long way to go. J Pediatr 2001;139:174-6. 
22 Patterson CC, Carson DJ, Hadden DR. Epidemiology of childhood IDDM in Northern Ireland 1989-1994: low incidence in areas with highest population density and most household crowding. Northern Ireland Diabetes Study Group. Diabetologia 1996:39:1063-9.

23 ISPAD Guidelines 2000. Zeist, Netherlands: Publ, Medforum, 2002.

24 Carstairs V, Morris R. Deprivation and mortality: an alternative to social class? Community Med 1989;11:210-19.

25 Freeman JV, Cole TJ, Chinn S, et al. Cross sectional stature and weight reference curves for the UK, 1990. Arch Dis Child 1995:73:17-24.
26 Paediatric Diabetes Special Interest Group. The role and qualifications of the nurse specialising in paediatric diabetes. London: Royal College of Nursing of the United Kingdom, 1993

27 National Institute of Clinical Excellence. CG15 type 1 diabetes: diagnosis and management of type 1 diabetes in children, young people and adults - NICE guideline. National Institute of Clinical Excellence, 2004.

28 Baumer JH, Hunt LP, Shield JP. Audit of diabetes care by caseload. Arch Dis Child 1997;77:102-7.

29 Baumer JH, Hunt LP, Shield JP. Social disadvantage, family composition, and diabetes mellitus: prevalence and outcome. Arch Dis Child 1998;79:427-30.

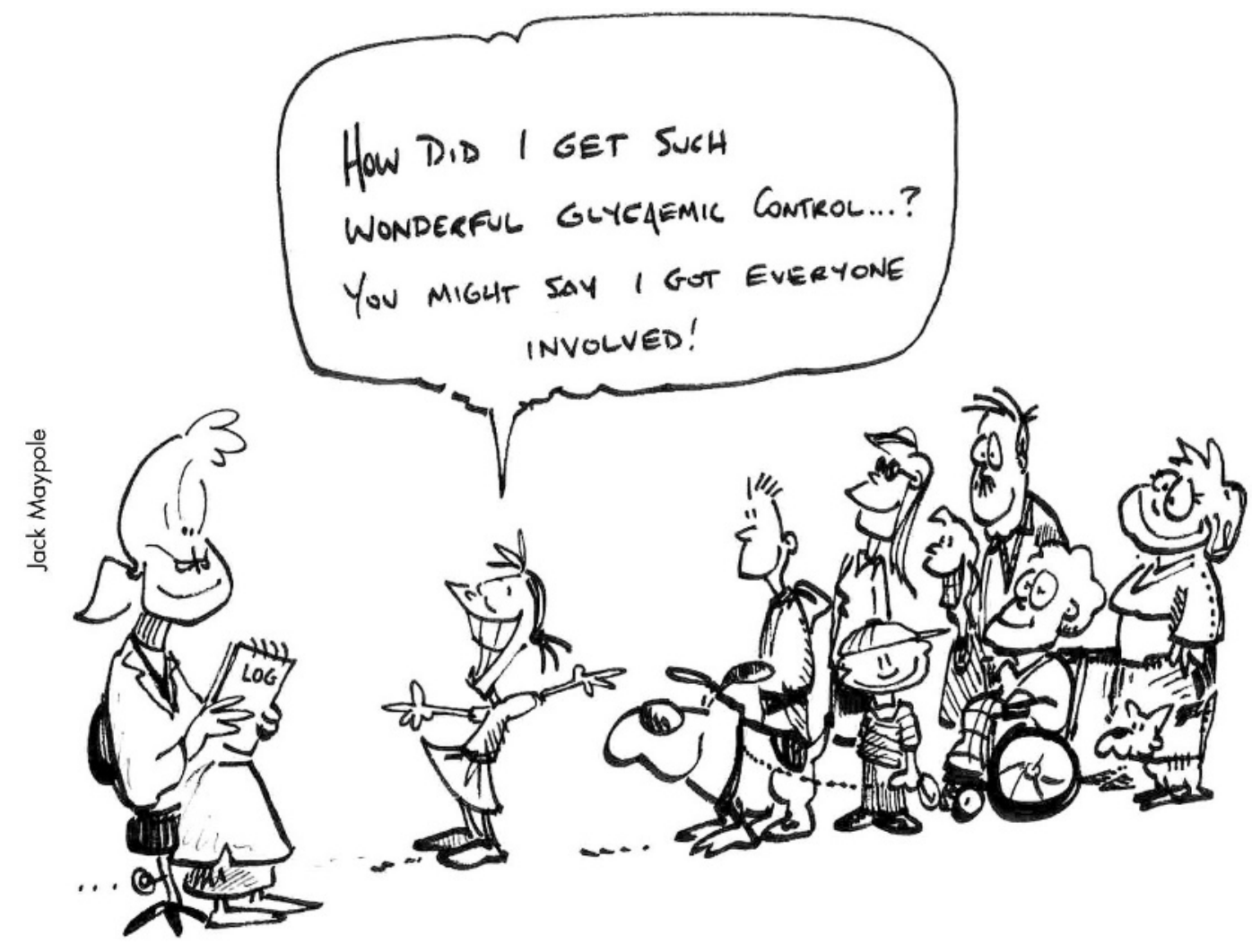

